\title{
Public participation and the moral quality of healthcare rationing
}

\author{
Len Doyal
}

Health services throughout the world do not have enough resources to meet the healthcare needs of all of their citizens. Therefore, some form of rationing within health services is inevitable. ${ }^{1}$ Even within healthcare systems in which access to health care is guaranteedhowever they are funded-this will mean that some who are ill will not necessarily receive treatment when they need it, if at all. The moral quality of health care delivered in such circumstances of scarcity will depend on the fairness and justice with which such decisions are made.

Equally, within democracies citizens should be able to participate in decision making about issues which affect their vital interests. Access to appropriate health care is clearly one of the most important of such interests. On the face of it, therefore, the way in which scarce health care resources are distributed between those who need them is an obvious candidate for a democratic mandate. In attempting to come to grips with the moral problems posed by the necessity for healthcare rationing, governments in other countries have endorsed the importance of public participation in setting priorities in healthcare spending, as have other commentators. ${ }^{2-4}$

In this paper, I will argue that whereas the involvement of the public is crucial for the effective and efficient practice of health care, it has a limited role in making decisions about healthcare rationing. Some forms of rationing will be shown to be morally wrong, irrespective of their actual or potential popularity.

\section{Importance of democratic participation in public life}

Democratic forms of social organisation presuppose two things: that citizens have a right to participate in the way in which they are governed and that they all have this right in equal measure. Historically, the primary moral justification for equal rights was protection from the arbitrariness of despotism. Yet this concern was balanced by the anxiety about extending citizenship to the poor and uneducated who might exercise their democratic rights irresponsibly. The extension of suffrage in Europe was accompanied by a growing recognition that it was unreasonable to expect people without political experience to support democracy unless they were given the right to learn and mature through participating in it. ${ }^{5}$

Current writers on democratic participation in the formulation of public policy make the same point. ${ }^{6}$ Despite the existence of universal suffrage, the creation and implementation of such policy increasingly occurs in the face of public passivity. This is hardly surprising.
Many citizens feel that all they can do to exercise their democratic rights is to elect politicians who move beyond their democratic influence. Elections themselves can cover so many issues that local concerns about specific issues become lost in the generalities of party politics. $^{7}$

Methods have been proposed to deal with this problem through involving the public more in local decision making. They include citizens' juries, issues forums, and deliberative opinion polls on national issues, as well as other approaches to create consensus and shared vision among groups seeking a voice in local policy formation. All of these approaches recognise that citizen led democracy must be informed to be effective. ${ }^{8}$ Citizens' juries, for example, involve the selection of representative people from different social groupings to whom resources are made available for educated and reasoned debate on particular issues. Jurors have more direct stake in policy formation than ordinary voters as their conclusions must receive a formal and public response by the authorities that organise them. ${ }^{9}$

Such innovations in the theory and practice of democracy are to be applauded. Decisions about public policy have been dominated for too long by experts with specialised knowledge of types of human need but little awareness of how these are experienced by people in varying circumstances. This top down control engenders political passivity as well as stifling the bottom up feedback required for monitoring the effectiveness, efficiency, and fairness of policy decisions. A dual strategy of democratic representation is required to include both expert and experiential understanding in policy formation. ${ }^{10}$

Yet it does not follow from the importance of expanding democratic participation in the political process that local majorities should be given unlimited scope about what they decide on behalf of others. To be fair, few have explicitly argued for such an approach. However, the justifications for constraining the power of local democracies have usually focused on their inadequate resources for proper deliberationfor example, poor access to all relevant information. The implication, therefore, is that the power of the public should be greatly increased were these problems to be resolved. ${ }^{11}$ Here I wish to argue in principle for limits to be set on such power. However effective local democracy may be in eliciting informed participation, there will still be boundaries of democratic decision making which should not 
be crossed unless democracy itself is to be undermined.

\section{Public participation in healthcare rationing: the problem}

Policy makers within health care face difficulties if they attempt to transfer the responsibility making for the moral quality of healthcare rationing from themselves to the public. As an example of why, let us consider the role of the public in rationing health care within the National Health Service (NHS) in Britain.

There can be little doubt that the NHS faces serious problems of scarcity, of not having enough resources to meet growing demand. ${ }^{12}{ }^{13}$ In Britain, for example, many health authorities have had to make swingeing cuts over the past year and some hospitals are close to bankruptcy. Bed numbers and clinical sessions have been reduced to the point that in many areas no elective interventions are being performed. While patients with serious conditions are being kept waiting for unacceptable, and for some of them agonising periods of time, ways are also being found to keep patients in need off waiting lists altogether. The problems accumulate.

Some commentators continue to argue that such indicators do not necessarily represent a crisis in NHS funding. However, the fact remains that Britain continues to spend less per capita on health care than other comparable developed nations. ${ }^{14}$ There is little doubt that many citizens in obvious need of health care have had to do without-either altogether or for long and distressing periods. Many who receive care from the NHS and most who work in it agree that resources are scarce and times are hard.

Of course, there is nothing new in all this: the health service has never had enough to go around. ${ }^{15}$ What is new is the volume of apparently unmet need and the increasingly public character of the rationing that now occurs. Before recent government reforms, rationing decisions were often camouflaged as clinical judgements rather than what they generally are-judgements by clinicians which may or may not be morally acceptable. Through the so called "internal market" they now become the responsibility of two groups. Firstly, there are managers or "purchasers" who must meet local need through designated budgets. Secondly, "providers" in the form of clinicians must allocate assigned clinical sessions between themselves and patients. ${ }^{15}$ The preceding government dictated that the purchaser's criteria for macroallocation should be transparent and that the public should have a voice in their determination. ${ }^{2}$ Microallocation between people continues to remain clouded by the myth of moral neutrality in the exercise of clinical judgement. ${ }^{16}$ The most recent proposals of the new government are for the preceding policies to be replaced - among other things - by a system of "commissioning" rather than "purchasing". However, these changes will have no bearing on the moral arguments considered here. ${ }^{16 a}$
Various democratic initiatives have occurred in healthcare planning which mirror the more general approaches to local democracy already described. Attempts have been made to organise groups of citizens to solicit their views about (among other things) how much spending should be directed to different areas of clinical care. This has included whether some areas should receive no funding at all and be excluded from the NHS tariff. ${ }^{17}{ }^{18}$ These initiatives as well as opinion polls on the same topic have yielded similar lists of clinical conditions deemed either not worthy of medical treatment or much less worthy than other types of clinical need. ${ }^{19}{ }^{20}$ Equally, local groups have debated whether or not the risky lifestyle of some people should qualify their right of equal access to health care. ${ }^{17}$

It has become clear that such public consultation can irrationally be influenced by the way in which policy questions are selected and worded for consideration, who presents the options to be considered, and of course, the socioeconomic background of participants themselves. $^{21}$ Yet the underlying message of some commentators and health authorities remains the same: provided that these problems can be tidied up; representatives of the public should be able to participate in decisions about which areas of health care are funded and who should receive that care.

Much the same picture emerges in debates about the rationing of health care within some but not all other countries. For example, over the past decade, governments and healthcare systems in the United States, Canada, Sweden, The Netherlands, and New Zealand have all witnessed initiatives to find more ways of transparently dealing with problems of scarce resources. ${ }^{22}$ Irrespective of the particular system of finance in force, everything from single payers to other types of internal markets, and private insurance systems, the public has purportedly been given a role in the determination of priorities. This is usually defendedwhatever the difficulties that emerge-with reference to the right of the public to participate in deciding policies about resources which the public has itself generated. ${ }^{8}$

Other countries facing similar problemsFrance, Italy, and Spain, for example-seem less enthusiastic about such participation with decision making being more admittedly centralised and top down. ${ }^{24}$ Should we argue that one or other approach to achieving moral quality in healthcare rationing is correct or should we look for some kind of balance between them?

\section{Good citizenship and the equal right to health care}

We have seen that arguments supporting public participation in the formation of social policy link it to the exercise of good citizenship. It is through such participation that citizens improve their potential contribution to democratic decision making. Yet some social policy is not compatible with good citizenship because it places arbitrary limits on the personal capabilities required to be a good citizen. ${ }^{25}$ Even the 
majority should not be allowed democratically to ration health care if the result is artificial constraints on the ability of the minority to be good citizens.

Whatever our cultural environment, we evolve and flourish as individual people through our social interaction with othersthrough our potential for successful social participation. It is through interaction with others that we learn and have reinforced those cognitive and emotional skills that constitute our personal identity. The more we can and do engage in social participation, the more we learn about who we are and what we are capable of. This in turn will enable us to optimise our contribution to the very social processes from which we have derived personal benefit. Thus anything that disables the potential for successful social participation counts as fundamental harm to those people involved. ${ }^{10}$

Such disability is often the result of serious physical and mental illnesses which prevent people from engaging in successful social participation. Such illness renders people less able to act and interact in ways which characterised their private and public life before illness. Their ability to join, continue, or improve their democratic participation in the political process will also be compromised. Illness not only harms the sick person but also the democratic polity which cannot benefit from their potential contribution. Thus it is self defeating in the name of more effective democracy to allow one group of citizens to restrict the access of others to needed health care. ${ }^{10}$

The fact that such a group may constitute a majority of decision makers is irrelevant if its decisions about rationing undermine the ability of members of the minority to be the best citizens they can. And the irrationality does not stop here. To allow majorities to dictate the health care received by minorities is imprudent for all citizens. Aside from the very wealthy, we all live under a veil of ignorance of the personal impact of unforeseen serious illness. Members of majorities may think that they will never contract disabling illness which they identify with the unlikely misfortune of minorities. Fate may dictate otherwise. As so many Americans have recently learned, people can never be sure of fair access to needed health care without $(a)$ universal cover and $(b)$ the certainty that no one can arbitrarily strip them of it. ${ }^{26}$

Allowing the public to jeopardise the physical and mental security of their fellow citizens is not only irrational; it is dangerous. If the majority of citizens are allowed to deny unpopular treatments to members of minorities in serious need-or to people whose lifestyles do not find favour-where will it end? If the only justification is that this is what the majority prefer then it would follow that it would be just as appropriate for the majority to deny treatment to the sickest $1 \%$ of the population. And if $1 \%$ why not $10 \%$ ! In Britain, for example, if the comeback is that the British would never engage in such injustice, the fact is that they have already. Some treatments are unavailable on the NHS tariff in one sixth of health authorities. ${ }^{27}$
Paradoxically, the rejection of the right of a majority of the public to restrict resources to a minority will make the need for rationing more acute - even for that minority. In such circumstances, the fairness of the distribution which does occur becomes of the utmost importance. It was against the background of arguments of citizenship of the sort already outlined that fairness within the NHS became defined by one substantive moral principle: equal access to scarce resources on the basis of equal need. ${ }^{28}$

The procedural implications of this principle (which I have discussed at length elsewhere) are that scarce resources should be allocated; ${ }^{29}$

- To meet need in proportion to its distribution within the population. This distribution should be documented through properly resourced and optimally accurate needs assessment. Epidemiologically, need should always be linked to evidence of serious disability in relation to social participation and better ways should be found to measure this.

- Without prejudice to the type of need or health care appropriate to satisfaction. Rationing should occur within and not between components of health care. Social participation is seriously impaired by any of a range of conditions for which treatment has not found public favourfor example, certain types of infertility. Those with these conditions have the same moral claim on resources as anyone else.

- According to moral similarity based on extremity of need. Such similarity is determined through improved methods of triage which should always be linked to assessing levels of impaired social participation. Those in most serious need should be treated first. Criteria for distribution other than urgency and similarity of need should be rejected.

- So that there is equality of access based on extremity of need. The implementation of such access should occur through the administration of fair waiting lists among those with morally similar needs. This method of distribution is fair because it is a form of randomisation based on the time of appearance and seriousness of needthe "lottery of nature"-rather than other personal attributes.

- Only for treatments of potential effectiveness. Medical or surgical intervention may be futile because of the untreatable condition of specific patients or general lack of clinical success. Offering such treatment in the face of either circumstance is inequitable as it wastes resources which could be used in the potentially successful care of others.

- Without reference to the lifestyle of recipients. Choices of lifestyle are shaped by different levels of understanding, emotional confidence, and social opportunity which are determined by varying social background which are partly beyond the control of those concerned.

A real commitment to an optimally successful democracy based on equal rights of 
participation demands support for the fair delivery of optimally successful health care to all citizens within that democracy. This commitment-to the moral quality of the justice embodied in the delivery of scarce healthcare resources - should be no more subject to alteration by the public than by the clinicians, managers, and policitians who run existing systems of healthcare delivery. ${ }^{30}$

Finally, substantive moral and procedural principles on their own solve few problems, and principles for rationing health care are no exception. They must be interpreted and there will be disagreement about how to implement them in practice-for example, about where to draw the line between minor and serious disability and between different categories of triage. For the moral goals of the health service to remain intact, such disagreements must be resolved as rationally as possible. Rules of representation, communication, and debate are required which ensure relevant knowledge of the problem at hand, minimise the influence of arbitrary bested interests, and maximise the opportunity for all participants to express their views. ${ }^{10}$ If the goal is an optimally rational and moral health service-for health care of the highest moral quality-these further procedural rules of communication also designate the boundaries beyond which democratic decision making should not be allowed to proceed.

\section{The positive role of public participation in health care}

These arguments against allowing democratic majorities to determine the substance or procedure of healthcare rationing do not entail that the public has no role in healthcare planning and monitoring. Their participation and experiential understanding are crucial. ${ }^{9}$ Examples of this include:

- Better needs assessment. We require much more accurate epidemiological information about the scope and types of serious disability faced by local populations. ${ }^{31}$ Also required is more conceptual and empirical clarification about the ways in which such disability is manifest, especially in relation to its impact on the potential for successful social participation. Without the involvement of patients, carers, relatives, and friends, this would be impossible. ${ }^{32}$

- Better audit and research. The clinical satisfaction of the basic need for physical and mental health will always occur against the background of current understanding of best treatment. It is now clear that the evidence base for such understanding is often lacking and that audit and research are a vital component to both the efficient and effective use of resources. Neither form of investigation is possible without the active participation of the public. Indeed, a particularly important part for the public to play is suggesting new inquiries which might not otherwise be apparent to health professionals too close to their immediate clinical and research interests. ${ }^{33}$
- Better defence of patients' rights. Patients are concerned about more than the clinical effectiveness of treatments on offer. They also expect that their autonomy will be taken seriously, particularly their right to informed consent and confidentiality. The participation of the public-through triggering the various avenues of complaint and regulation and active involvement in subsequent inquiries - is crucial for moral audit of this aspect of clinical practice to be effective. ${ }^{34}$

- More equity. Where consistency with first moral principles does not prevail, inequity will result. This may be because the experiences of the recipients of health care are not sufficiently reflected in policy decisions about resources allocation. When inequity does occur, the public has a crucial part to play in stopping it by highlighting its existence and making political demands through appropriate democratic channels. There is no doubt that such channels need to be improved and that the criteria used for rationing should be made explicit and open to public scrutiny. ${ }^{35}$

The moral foundations of the delivery of fair and just health care not based on a system of fees for individual services are not up for democratic grabs and must be applied consistently to individual cases. In the process, rules of rational communication and debate must be respected and not altered as the result of public opinion or political pressure. Within this framework, the goal of an equitable health service can be achieved with the active participation and support of the public.

\section{Consequences for the participation of individual patients in rationing decisions about themselves}

We have argued that the public should not be the final arbiter of decisions about rationing health care. Similar arguments hold in the case of individual patients making demands on scarce resources. Estimates of the severity of disability associated with specific illnesses will be impossible without effective communication which accurately elicits and records the experiences of patients. Equally, patients' perception of the success of clinical interventions in reducing disability will be of importance for their own future prognosis and treatment, as well as adding to the evidence base of such intervention for others. The success of such communication will partly depend on the trust and the spirit of partnership which develops (or fails to do so) between patients and their clinical advisors. ${ }^{36}$

However, it does not follow from the importance of communication for a good clinical relation that the preferences of individual patients should be the determining factor in any decisions that have to be made about their access to particular treatments. Suppose that patients have actively participated in discussions about their clinical need and treatment options-discussions which could save money through their rejecting options which other 
patients might choose. ${ }^{37}$ Any further rationing decisions about whether or not they receive specific treatments or the order in which they do so should be determined only by procedural rules for optimising fairness of the sort which have been outlined. These will trump the understandable, though sometimes irrational, concern with self interest which sustained illness often brings about.

In such circumstances, patients may well demand resources which they do not need or to which their level of need does not entitle them at that point in time. Scarce clinical resources should never be used just because patients - or their relatives-want them. If a decision is made to withhold health care which patients and relatives think will be of benefit, clinical teams must be very sure that their clinical assessment of futility is accurate or their procedural justification is morally coherent for providing treatment at a later date. Here, the participation-and sometimes protestations - of their patients may be crucial for making a correct decision. Equally, however, part of the duty of care includes sensitive and coherent explanations of why treatment is not being offered (or discontinued) and why it is members of the clinical team, rather than the patient, who have ultimate responsibility for this decision.

\section{Conclusion}

The moral foundations of the delivery of health care do not depend on a majority vote or individual preference for their moral coherence. Their justification starts and finishes with the quality of moral arguments used, along with the empirical evidence referred to in such arguments. It follows that principles of equality and fairness in the rationing of health care should not be open to change on any other basis. Some rights must be protected from collective and individual arbitrariness. The right of access to appropriate health on the basis of equal need is one of them.

Thanks to Lesley Doyal for editorial heroics and to Bill New.

1 Ham C. Priority setting in health. In: K Janovsky, ed. Health policy and systems development. Geneva: WHO, 1996:25-41.

2 Stewart J. Innovation in democratic practice. Birmingham: Institutute of Local Government Studies, 1995:1-39.

3 Farrell C, Gilbert H. Health care partnerships. London: Kings Fund 1996:24-31.

4 Cooper L L, Coote A, Davies A. Voices off: tackling the democratic deficit in health. London: IPPR, 1995.
5 Gutmann A. Liberal equality. Cambridge: Cambridge University Press 1980:48-63.

6 Held D. Models of democracy. Oxford: Polity, 1996:295-324. 7 McLean I. Forms of representation and systems of voting. In: Held D, ed. Political theory today. Oxford: Polity, 1991: 172-96.

8 Stewart J. Further innovation in democratic practice. Birmingham: Institute of Local Government Studies, University of Birmingham, 1996.

9 Stewart J, Kendall E, Coote A. Citizen juries. London: Institute of Policy Studies; 1994.

10 Doyal L, Gough I. A theory of human need. London: Macmillan, 1991:297-309;49-75;116-47.

11 Pfeffer N, Pollock A. Public opinion and the NHS. BMF 1993;307:750-75.

12 Boyle S, Harrison A. Financial meltdown for the NHS? BMF 1996;312:1432-3.

13 Dixon J, Harrison A. Funding the NHS: a little local difficulty? $B M F$ 1997;314:216-9.

14 Crail M. How the tables have turned. Health Services fournal, 1995;16 February: 14-15.

15 Klein R, Day P, Redmayne S. Managing scarcity: priority setting and rationing in the National Health Service. Buckingham: Open University Press, 1996:37-45;83-93.

16 Kennedy I L, ed. What is a medical decision. In: Treat me rights: essays in medical law end ethics. Oxford, Clarendon Press, 1988:19-31.

16a The new NHS. London: The Stationery Office, 1997. (Cm 3807.)

17 Bowie C, Richardson A, Sykes W. Consulting the public about health service priorities. BMF 1995;311:1155-8.

18 Stewart J, Honigsbaum F, Richards J, et al. Priority setting in action: purchasing dilemmas. Birmingham: Health Service Management Centre 1995:17-59.

19 Heginbotham C. Health care priority setting: a survey of doctors, managers, and the general public. In: Rationing in action. London: BMJ Publishing, 1993.

20 Bowling A. Health care rationing: the public's debate. $B M \mathcal{F}$ 1996;12:670-67.

21 Jacobson B, Bowling A. Involving the public: practical and ethical issues. In: Maxwell R, ed. Rationing health care. London: Churchill Livingstone, 1995:869-75.

22 Klein R, Day P, Redmayne S. Managing scarcity. Buckingham: Open University Press, 1996:108-19.

23 Withdrawn.

4 Lenaghan J. Hard choices in health care. London: BMJ Publications, 1997:48-67,112-42,160-76.

25 Plant R. Citizenship and rights. In: Milligan D, Miller W, ds, Liberalism, citizenship and autonomy. Aldershot: Avebury, 1992:108-33.

26 Dworkin R. Will Clinton's plan be fair? New York: Review of Books. 1994; January 13:20-5.

27 Redmayne S. Reshaping the NHS: strategies and priorities and resource allocation. Birmingham: National Association of Health Authorities and Trusts, 1995.

28 Stacey M. The sociology of health and healing. London: Unwin Hyman, 1988:116-32.

29 Doyal L. Needs, rights, and equity: moral quality in healthcare rationing. Quality in Health Care 1995;4:273-83.

30 Lenaghan J. Rationing and rights in health care. London: IPPR, 1996:25-64.

31 Williams G, Popay J. Researching the people's health: dilemmas and opportunities for social scientists in researching the people's health. London: Routledge, 1994:99-114.

32 Pfeffer N, Coote A. Is quality good for you? London: Institute for Public Policy Research, 1991:45-58.

33 Percy-Smith J, Sanderson I. Understanding local needs. London: Institute for Public Policy Research, 1992.

34 Doyal L. Need for moral audit in evaluating quality in health care. Quality in Health Care 1992;1:178-83.

35 Doyal L, Rationing within the NHS should be explicit: the case for. BMF 1997:314;114-8.

36 Davis H, Fallowfield L, eds. Counselling and communication in health care. Chichester: John Wiley, 1991:3-22.

37 Goodare H. Possibilities for direct patient involvement in rationing decisions. In: B New, ed. Rationing: talk and action. London: BMJ Publishing Group, 1997: 164-70. 